\title{
Recorregut de recerca geològica i mineralògica per la comarca de l'Alt Urgell: des de Sant Joan Fumat i a les Bordes de Conflent i a Aós de Civís
}

Josep Maria Mata-Perelló

Joaquim Sanz Balagué

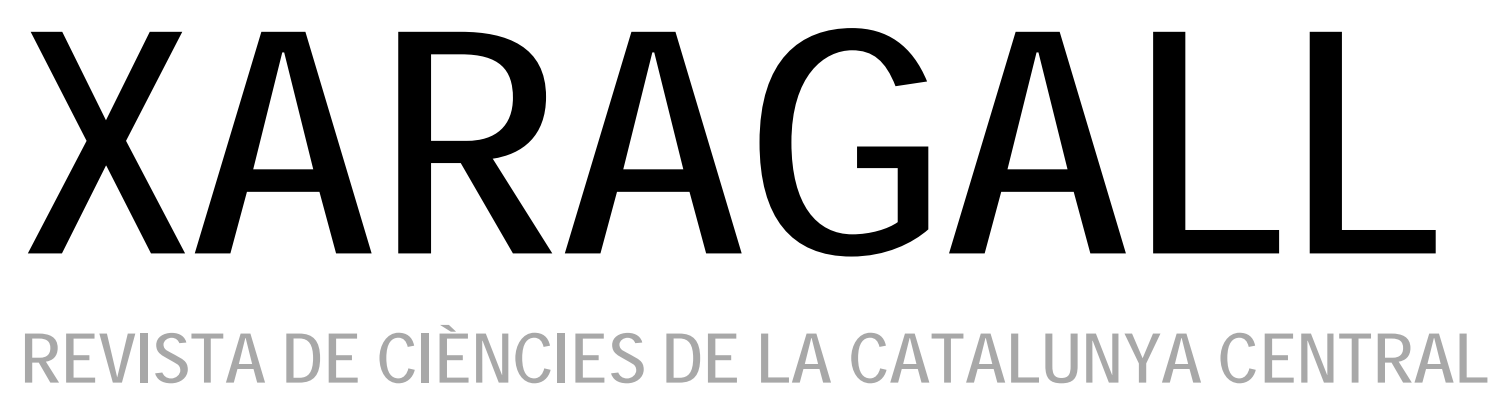

ก. 6

JUNY 2015 


\title{
RECORREGUT DE RECERCA GEOLÒGICA I MINERALÒGICA PER LA COMARCA DE L'ALT URGELL: DES DE SANT JOAN FUMAT I A LES BORDES DE CONFLENT I A AÓS DE CIVÍS
}

\author{
Josep Maria Mata-Perelló \\ Museu de geologia Valentí Masachs, Escola Politècnica Superior d'Enginyeria de Manresa \\ (EPSEM), Universitat Politècnica de Catalunya - BarcelonaTech (UPC), 08272 Manresa, Spain
}

\section{Joaquim Sanz Balagué}

Departament d'Enginyeria Minera i Recursos Naturals (EMRN), Escola Politècnica Superior d'Enginyeria de Manresa (EPSEM), Universitat Politècnica de Catalunya . BarcelonaTech (UPC), 08272 Manresa, Spain

Paraules clau: Sistema Pirinenc, Patrimoni miner

\section{Resum}

Itinerari realitzat el 14 de juliol de 2014. En aquesta ocasió, el recorregut de l'itinerari discorrerà íntegrament pel Sistema Pirinenc; i més concretament per la Unitat dels Apilaments Antiformes de la Zona Axial, (és a dir, per I'antigament denominada "Zona Axial Pirinenca").

Així, travessarà aquesta zona en el recorregut que es farà entre la Farga de Moles, les Bordes de Conflent i Aós de Civís; és a dir, es tallarà aquest sector en la major part del recorregut de l'itinerari. Així, al llarg de tot l'itinerari es trobaran afloraments dels materials de l'Ordovicià (amb esquistos, quarsites i calcosquistos) i del Silurià amb pissarres negres, fonamentalment). També trobarem aflorament de les granodiorites del Carbonífer.

Per altra banda, el recorregut de l'itinerari discorrerà per una sola comarca, la de I'Alt Urgell, entre la Farga de Moles, Sant Joan Fumat, les Bordes de Conflent i Aós de Civís. 


\section{Objectius fonamentals}

Els objectius fonamentals d'aquest itinerari es poden concretar en els següents aspectes, d'acord amb el sentit de la marxa:

1. Estudi i reconeixement dels materials paleozoics (de l'Ordovicià al Carbonífer) que formen part dels relleus dels anomenats Apilaments de la Zona Axial Pirinenca. Aquests materials es reparteixen, segons els indrets entre I'Ordovicià i el Silurià. Tanmateix, trobarem afloraments de les granodiorites del Carbonífer.

2. Reconeixement de deferents mineralitzacions situades al llarg del recorregut: com les següents:

2A) de les mineralitzacions filonianes associades a zones de fractura, de $\mathrm{Fe}-\mathrm{Cu}$ (amb SIDERITA i CALCOPIRITA), de les Bordes de Conflent, també a l'Alt Urgell.

3A) les mineralitzacions filonianes de coure (de CALCOPIRITA), situades a Aós de Civís, dintre de l'Alt Urgell.

3. Reconeixement de les explotacions mineres, antigues i actuals, relacionades amb les mineralitzacions esmentades a l'apartat anterior.

4. Observació dels impactes produïts per les explotacions anteriors, sobre el Medi Natural.

5. Observació dels indrets relacionats amb el risc geològic, que anem trobant al llarg del recorregut de l'itinerari.

6. Observació, al llarg del recorregut, dels diferents indrets relacionats amb el Patrimoni Geològic i també dels relacionats amb el Patrimoni Miner.

\section{Antecedents}

$\mathrm{Hi}$ ha alguns antecedents parcials en relació al recorregut d'aquest itinerari, que coincideixen amb part del recorregut d'altres itineraris del mateix tipus, a MATA-PERELLO (1991, 1995a, 1995b i 2006). Pel que fa a les mineralitzacions, cal dir que han estat estudiades per nosaltres mateixos, i publicades en: MATA-PERELLÓ (1990).

I, finalment, pel que fa a les estructures pirinenques, existeixen alguns antecedents, a: GUIMERÀ et altri (1992), i a RIBA et altri (1976).

En tots els casos, ens remeti'm a l'apartat dedicat a la BIBLIOGRAFIA, el qual es troba al final d'aquest treball. 


\section{Recorregut de l'itinerari}

L'itinerari s'inicia pels voltants de la Farga de Moles, des d'on es deixarà la carretera d'Andorra, i es continuarà pel camí de Sant Joan Fumat. Des d'aquest poble, es continuarà cap a Ras i cap a les immediacions del Ras de Conques, per on es farà un altra parada.

Després s'anirà cap a les Bordes de Conflent, on es farà una nova parada a les mines de Fe$\mathrm{Cu}$. En aquest darrer indret finalitzarà el recorregut de d'itinerari, molt proa del límit entre les comarques de I'Alt Urgell i del Pallars Sobirà, però dintre de la primera.

I finalment, el recorregut es dirigirà cap el poble d'Aós de Civís, per on es farà la darrera aturada d'aquest itinerari, finalitzant aquí el recorregut de l'itinerari, camí d’Andorra.

\section{Advertiments previs}

Com en altres recorreguts de RECERCA GEOLÒGICA I MINERALÒGICA... si es disposa del temps suficient, poden efectuar-se passant per totes les parades i filloles. En cas contrari, recomanem prescindir de les anomenades PARADES - CONDICIONALS.

En aquesta sortida de recerca geològica i mineralògica, presentarem un recorregut general, que discorrerà tant per carreteres, com per pistes forestals (com el que ens aproparà cap a les Mines de Conflent). Si s'escau, es prescindirà d'algun tram, en funció de l'estat dels camins, i del tipus de vehicle utilitzats.

Com en altres ocasions, recomanem i demanem el màxim respecte per a la natura que ens envolta, al llarg de tot el recorregut de l'itinerari i també en tot moment.

\section{Descripció de l'itinerari}

En aquest recorregut hem situat, com ja és habitual en tots els itineraris, una sèrie d'ESTACIONS o de PARADES, que anirem veient a continuació. En cada cas, els hi donarem una denominació que podrà correspondre a algun paratge proper. També indicarem el terme municipal i la comarca on es troba.

Per altra banda, en cadascuna de les parades, indicarem entre parèntesi el número del mapa topogràfic, a escala 1:50.000, on es troba situada la parada considerada. Així, en aquesta ocasió utilitzarem una doble nomenclatura: per una banda, si s'escau, utilitzarem algun dels dos fulls següents de la "Cartografia Militar de España": 182 (o de Tírvia), 183 (o d’Andorra) i 215 (o de la Seu d'Urgell).

Així, passarem a continuació, a fer una referència ordenada, de les diferents aturades que composen el recorregut del present itinerari. 


\subsection{Parada 1. COLLET DE RAS DE CONQUES, (antic terme de Civís, a l'actualitat del de les Valls del Valira, l'Alt Urgell). (Full 215).}

El recorregut el començarem per les immediacions de la Farga de Moles. Abans d'arribar-hi, venint des de la Seu d'Urgell, es troba per l'esquerra el trencall que condueix cap a Sant Joan Fumat. Des d'aquí cal seguir cap al poble d'Ars, per tal de continuar cap al Ras de Conques, en arribar al collet farem una nova aturada, per sobre del camí, a uns $10 \mathrm{Km}$ de la parada anterior.

En aquest recorregut, hem anat trobant afloraments materials paleozoics que formen part dels Apilaments Antiformes de la Zona Axial Pirinenca, la unitat on estem situats. Així, en un principi, haurem vist afloraments dels nivells d'esquistos de l'Ordovicià, però també trobarem afloraments de les pissarres negres del Silurià (en especial entre Sant Joan Fumat i Ars) i de les calcàries del Devonià, com per les immediacions d'on ara som.

Aixa, en aquest lloc, estem situats al contacte entre les pissarres del Silurià i les calcàries del Devonià. Precisament, en aquest $\|$ oc, entre les pissarres negres hi ha una interessant mineralització uraninífera associada a "red-bed", amb presencia d'AUTUNITA, CARNOTITA i TORBERNITA, a més a més d'URANINITA (en forma de PECHBLENDA, molt alterada). Al respecte d'aquesta mineralització, cal dir que cap als anys 60, la Junta de Energía Nuclear, va realitzar una cata de reconeixement.

Per d'altra banda, entre els materials de I'Ordovicià, prop d'on som, també es fan paleses les concentracions d'oxxids de ferro, associades a nivells de calcosquists. En aquestes es fa força evident la GOETHITA (la qual apareix en forma limonita) així com I'HEMATITES. (fotografia 1).

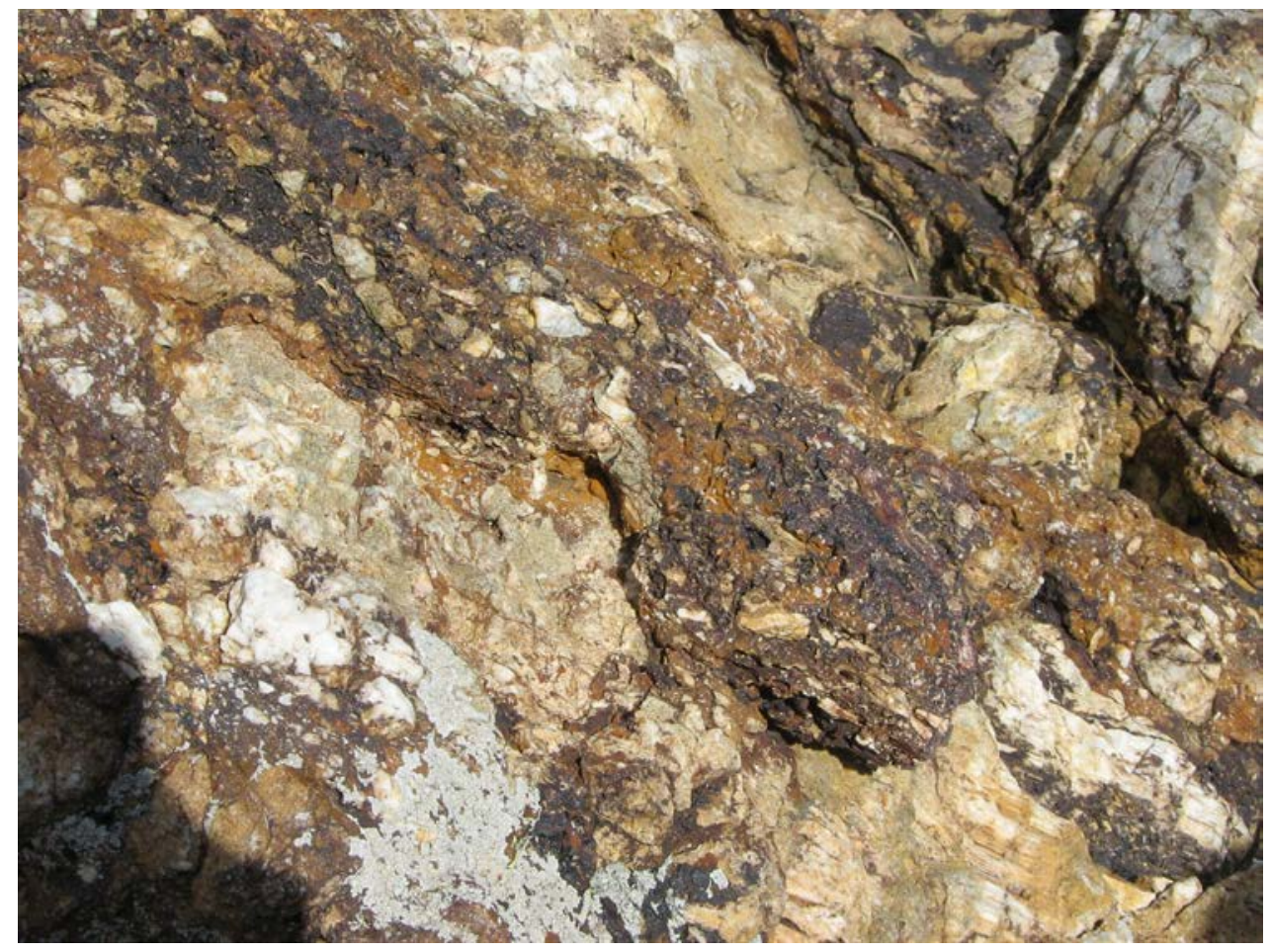

Fotografia 1. Concentracions d'òxids de ferro, Ras de Conques 


\subsection{Parada 2. MINES DE LES BORDES DE CONFLENT (antic terme de Civís, i ara del de Valls del Valira, comarca de I'Alt Urgell). (Full 215).}

Des de la parada anterior, és necessari continuar pel camí que s'està seguint, per tal de baixar cap a Santa Magdalena. En arribar-hi, caldrà remuntar el Barranc de Conflent, per tal d'arribar a les Mines de les Bordes de Conflent, per on farà una nova aturada d'aquest itinerari, a uns 7 $\mathrm{Km}$ de l'anterior aturada.

En aquest recorregut, haurem anat trobant els materials paleozoics de la Zona d'Apilaments de la Zona Axial Pirinenca, on ens trobem des d'Anserall. Així, haurem trobat afloraments de I'Ordovicià, del Silurià i del Devonià. Els del Silurià, amb pissarres negres, s'hauran fet especialment palesos (i molestos de travessar), per tractar-se de materials molt plàstics, en els quals els camins es fan malbé.

En arribar a les Bordes de Conflent, caldrà anar a peu cap a les antigues mines, situades per sobre de les bordes, a la dreta del Barranc de Salòria de Finestres. També hi ha mines a l'esquerra del barranc, però ja dintre del terme de Farrera, al Pallars Sobirà.

Les mineralitzacions es relacionen amb zones de cisalla, de fracturació, entre els afloraments esquistosos de I'Ordovicià que es troben en aquest lloc, i que hem començat a tallar prop de les Bordes de Conflent.

La mineralització presenta un caràcter cuprífer i ferrífer alhora. Entre els minerals de $\mathrm{Cu}$ es troben. CALCOPIRITA (molt abundant), TETRAEDRITA, CUPRITA, TENORITA (indicis), ATZURITA i MALAQUITA.. I entre els de Fe, es troben: GOETHITA (limonita), HEMATITES ANQUERITA i sobretot SIDERITA.

També es troben altres minerals com. OR NADIU (indicis), ESFALERITA (indicis), GALENA (indicis), TETRADIMITA, PIRITA (molt abundant), PIROLUSITA, CALCITA i QUARS.

Finalment, cal dir que aquestes mines van ésser explotades durant el segle passat, per al benefici dels minerals de $\mathrm{Fe}$ i de $\mathrm{Cu}$. Tot i això, darrerament han estat recercades, de cara a conèixer el seu contingut en OR NADIU.

Pel que fa a les antigues explotacions mineres, cal dir que tot i que es troben força enrunades, encara es pot entrar en algunes galeries. Per d'altra banda, a les escombreres es poden trobar moltes mostres de minerals. (fotografies 2 i 3 ). 


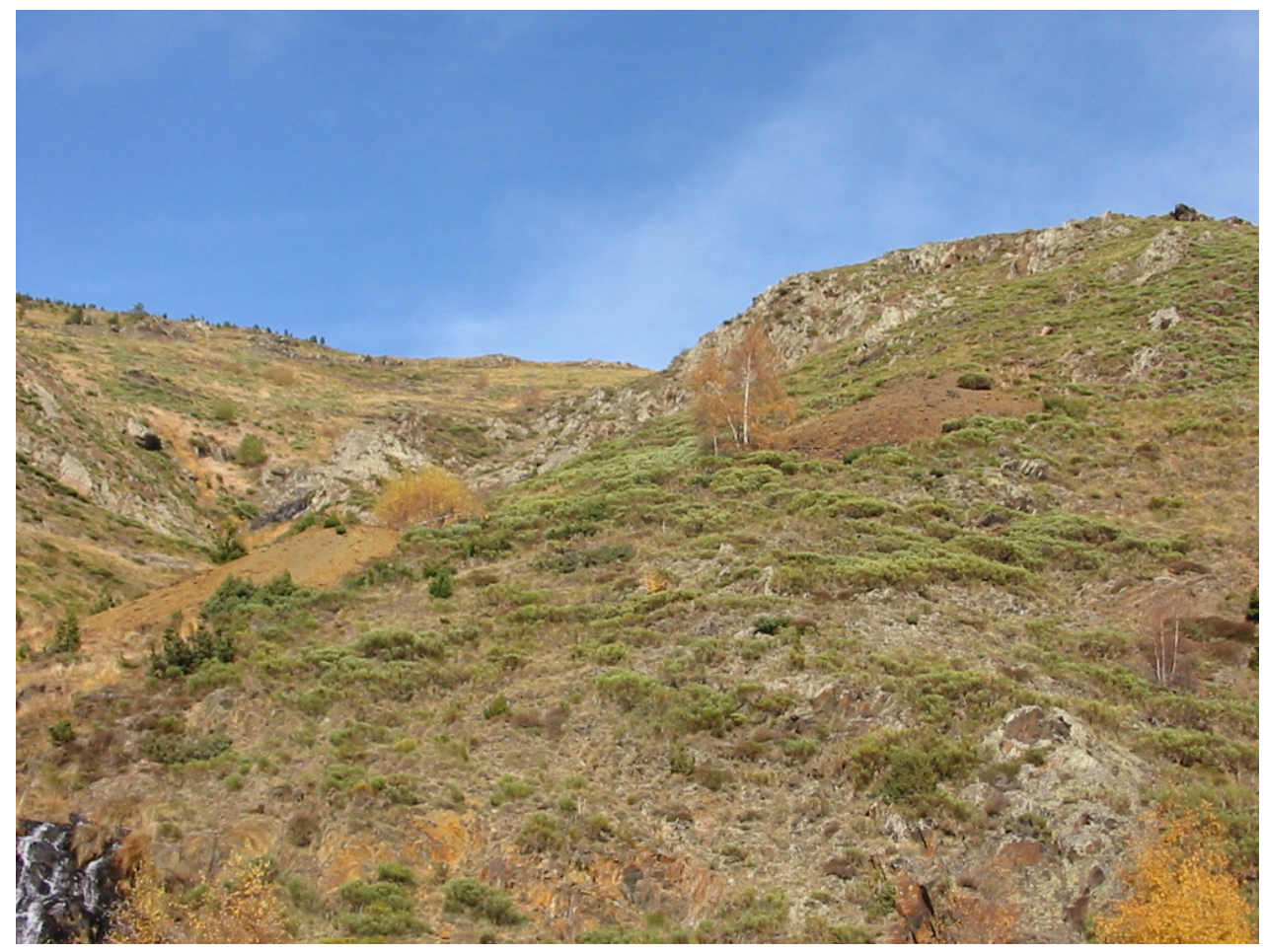

Fotografia 2. Un aspecte general de les Bordes de Conflent

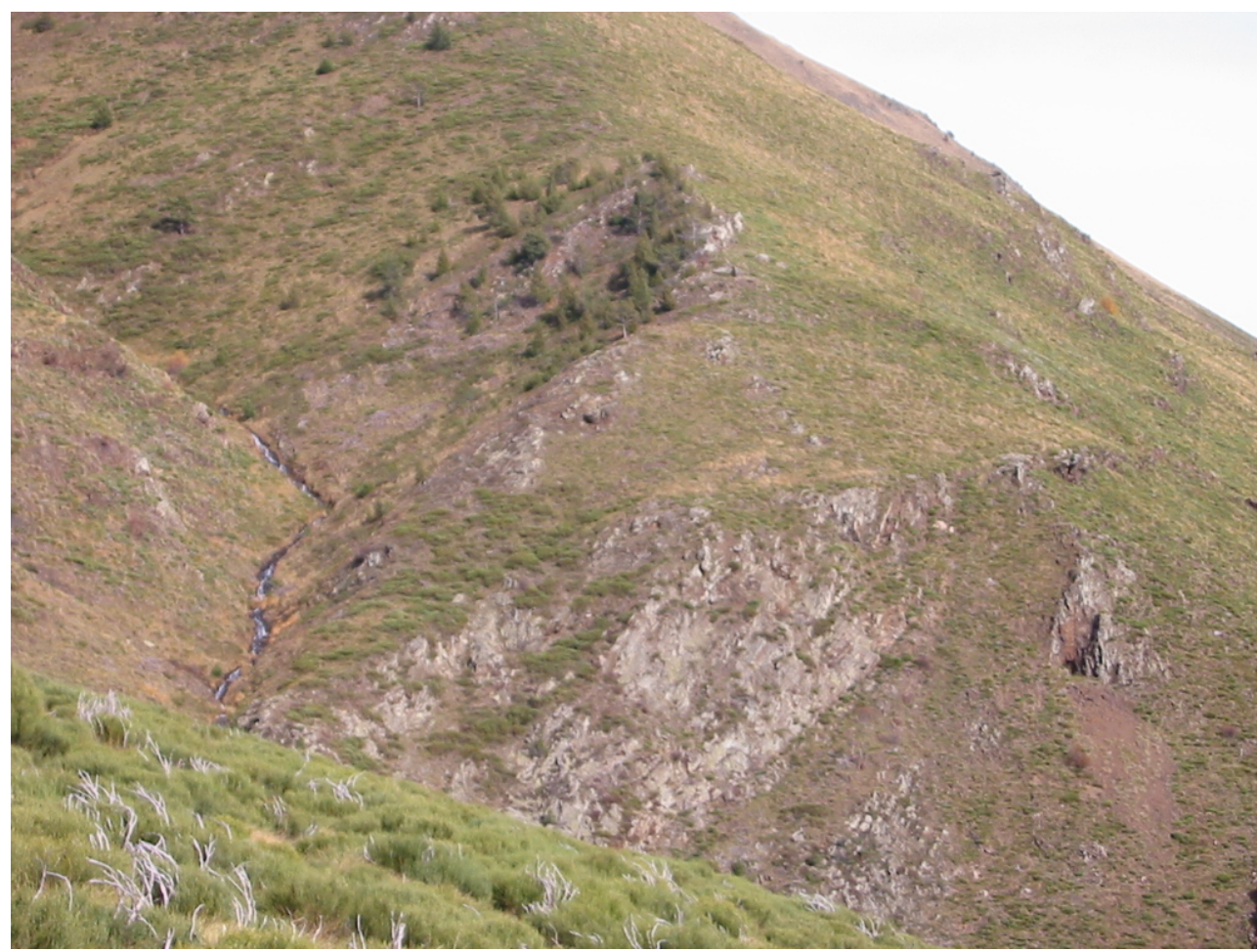

Fotografia 3. Un altre indret de les Bordes de Conflent, amb una de les bocamines Joan Fumat i a les Bordes de Conflent i a Aós de Civís 


\subsection{Parada 3. MINES DEL BARRANC DE SALÒRIA (Aós de Civís, de l'antic terme de Civís, ara pertany al de les Valls del Valira, comarca de I’Alt Urgell). (Full 182).}

Des de la parada anterior cal continuar pel camí de terra, cap a ponent. Així, aviat es sobrepassarà el Coll de Conflent, arribant-se poc després a les immediacions del poble d'Aós de Civís. Poc abans d'arribar-hi, a la Borda de la Plana, ens caldrà agafar el camí (per I'esquerra), el qual se'n va cap al Barranc de Salória. En arribar-hi (en un trajecte d'uns 2-3 $\mathrm{Km}$ ), ens caldrà fer la present aturada, després de recórrer uns 8-9 $\mathrm{Km}$, des de la parada anterior. mines.

Tot aquest recorregut, s'efectua antre els materials paleozoics de l'Ordovicià, ja esmentats a les dues parades anteriors. Tot i així, sovint es troben afloraments del Silurià, constituïts per nivells de pissarres piritoses, Igualment es tallen uns nivells carbonatats del Devonià, i uns altres d'esquistosos que pertanyen al Carbonífer, que inclouen uns afloraments granodiorítics. Tots aquests materials es situen dintre dels Apilaments Antiformes de la Zona Axial, per on estem situats des de l'inici del recorregut.

Les mines es situen sobre unes mineralitzacions filonianes, de direcció NW-SE, encaixades entre els esquists de l'Ordovicià. Els minerals més abundants són la CALCOPIRITA i el QUARS (especialment aquest darrer, ja que els filons són eminentment quarsífers).

També es troben altres minerals de coure, com els COURES GRISOS (indicis). Per d'altra banda, es troben diversos minerals cuprífers produïts per I'alteració dels anteriors com: CUPRITA (indicis), TENORITA (indicis), ANTLERITA (indicis), ATZURITA i MALAQUITA.

I, finalment, cal dir que també hi ha altres minerals presents com els següents: MARCASSITA, PIRITA, GOETHITA (terrosa i limonítica), HEMATITES (sempre terrós), PIROLUSITA, CALCITA i SIDERITA. Tanmateix hi ha presència d'indicis de SOFRE.

Les mines consisteixen en una sèrie d'explotacions, que van ésser treballades durant el segle XIX i principis del XX. Per d'altra banda, cal dir que a més a més de les mines ara visitades, n'existeixen altres situades riu amunt. En conjunt, es tracta d'una zona minera que va tenir una gran importància.

Ara, a l'actualitat, pràcticament totes les galeries es troben esfondrades, però encara es possible entrar en algunes de les antigues galeries. (fotografia 4). 


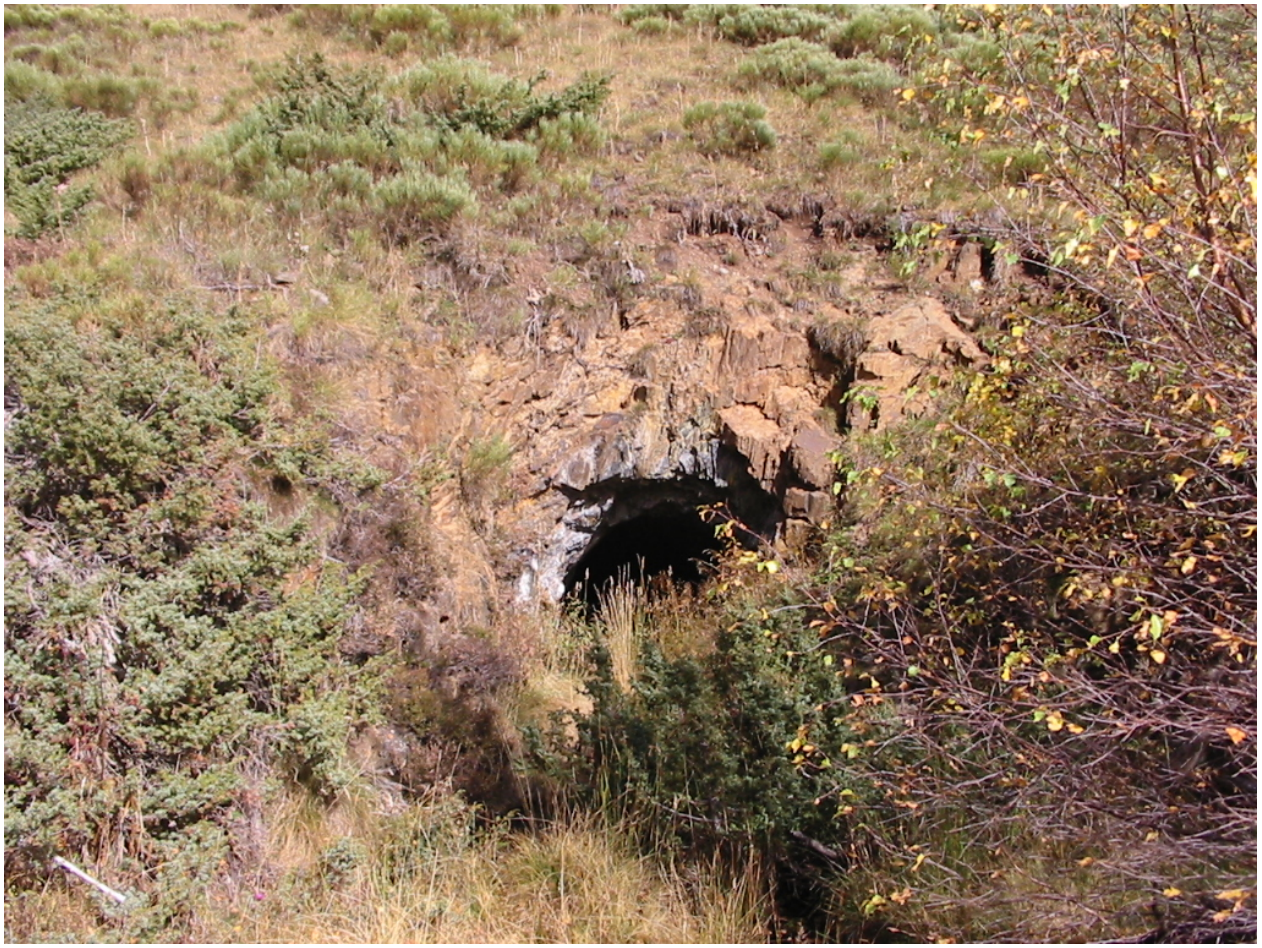

Fotografia 4. Una de les galeries de les Mines de Salòria. Aós de Civís

\subsection{Parada 4 - CONDICIONAL. TURONET DEL NORD DE CIVÍS (pertany a l'antic terme de Civís, a l'actualitat del de les Valls del Valira, comarca de l'Alt Urgell). (Full 215).}

Des de la parada anterior, cal acabar d'arribar fins al poble d'Aós de Civís. Des d'aquí cal continuar cap a ponent, fins arribar a Bixessàrri, passant així des de la comarca de l'Alt Urgell al principat d'Andorra. Després, des del poble anterior, cal anar cap al Santuari de Canòlic, per tal de continuar després per una pista cap al Coll de Canòlic. Des d'aquí, caldrà baixar cap al poble de Civís. En arribar-hi, caldrà agafar un corriol cap al Nord del poble, que en 5 minuts condueix cap a un turonet. Així, s' hauran recorregut uns $10 \mathrm{Km}$, des de la parada anterior.

En el recorregut, des de la parada anterior, hem anat trobant els materials de l'Ordovicià, constituïts per nivells d'esquistos i marbres. Tot i així, en arribar a Civís hem trobat els materials piritosos del Silurià. Precisament, entre aquests darrers materials hi ha la mineralització que observarem a continuació.

Al turonet anteriorment esmentat, es troben uns filonets piritosos que contenen abundants geodes amb cubs de PIRITA. Secundàriament la pirita s' ha alterat, i s' ha produït la formació de GOETHITA (la quals es troba en forma de limonita), MELANTERITA i SIDEROTíL. També es troba CALCITA i QUARS. Aquest darrer és molt abundant.

En aquest indret finalitza el recorregut de l'itinerari 


\section{Bibliografia}

GUIMERÀ, J. et altri (1992).- Geologia (II). Història Natural dels Països Catalans. Vol. 2, 547 pag. Enciclopèdia Catalana, S.A. Barcelona.

MATA-PERELLÓ,J.M. (1990).- Els Minerals de Catalunya. Arxius de la Secció de Ciències de I'Institut d'Estudis Catalans, vol.47, 545 pag. Barcelona.

MATA-PERELLÓ,J.M. (1991).- Itinerari mineralògic entre Castellciutat i Civís, per la Seu d'Urgell, Sant Julià de Loira i les Bordes de Conflent. But. Col. Ofi. Doc. Llic. Catalunya, $\mathrm{n}^{\circ} 74$, pp.20-24. Barcelona.

MATA-PERELLÓ, J. M. (1995a).- Itinerari geològico-mineralògic per I'Alt Urgell, Andorra i la Cerdanya: de la Seu d'Urgell a Ransol, a la Guingueta i a Grus. Xaragall, 36, 10 pag. Manresa.

MATA-PERELLÓ, J. M. (1995b).- Itinerari geològico - mineralògic per I’Alt Urgell i pel Pallars Sobirà: des d'Adrall a les Bordes de Conflent i a Sorriguera. Inèdit. 8 pag. Manresa.

MATA-PERELLÓ, J. M. (2006).- Recorregut de recerca geològica i mineralògica per la comarca de l'Alt Urgell: des d'Adrall a Sant Joan Fumat i a les Bordes de Conflent. Inèdit. 8 pàgines. Manresa.

RIBA ARDERIU, O. et altri (1976).- Geografia Física dels Països Catalans, Edit. Ketres. Barcelona. 